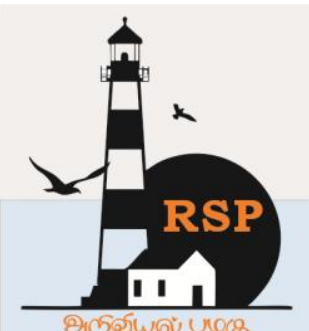

INTERNATIONAL RESEARCH JOURNAL ON ADVANCED SCIENCE HUB

Special Issue of First International Conference on Engineering, Science, and Technology (ICEST 2021)

\title{
Computing Wearable's Enabling Taking Body Measurements Physical to Digital
}

\author{
Ms. Shubhangi Yadav (Shinde), Dr. Bhawana Chanana
}

Lecturer in D. D. and G. M. Dept., Government Polytechnic, Pune, Maharashtra, India.,

Professor and Director, School of Fashion Design and Technology, Amity University, Mumbai, Maharashtra, India

shubhnandan@yahoo.co.in ${ }^{1}$

\begin{abstract}
If a device tells you whatever garment you are wearing is not the best fit for your body, would you change? If yes, then Computing wearable's are fosters for providing personal information to the wearer about their body measurements. In medical sciences computing wearables not only track your day to day health-related data but also help in effective implementation of prevention and treatment techniques. Online apparel shopping is an easy method, which consumes less time and you can find everything you need. Apparel fitment becomes a key between acceptance and disappointment. In India there are no standard size charts available so apparel manufacturers are using size charts as per their own understanding and research. This may irritate the customers while trying to identify appropriate size, and may result into rejections, return of apparel. According to recent studies, between 20-40\% of all online apparel purchased $70 \%$ is returned, only due to issues with fit alone, which costing fashion e-tailors millions. Here the Body measurements data generated through computing wearable's can be an innovative and interactive method for selection of right garment which may put conventional taking body measurements method out of the market.
\end{abstract}

Keywords: Computing wearable's, body measurements, fitment, apparel manufacturing industry, size chart

\section{Introduction}

The apparel manufacturing and textile industry of India has witnessed numerous developments in recent years. According to Ministry of India Annual report 2018-19, India is a 2nd largest exporter of apparel and textile globally after China. The share of apparel and textile in India's total exports stands at a significant $13 \%$ (2017-18). India is a share of $5 \%$ of the global trade in textiles and apparel and the growth of market is further projected to reach US\$225.7 Billion by 2024, growing vital contribution at a CAGR of $14.2 \%$ during 2019-2024. Since the past decades Indian apparel manufacturing and textile industry has shaped from embryonic stage to blossoming take off stage. The blooming fashion industry is based on technical advancement of apparel manufacturing and textile industry. Also many Indian fashion designers are contributing in making India a home pitch, pioneer in fashion industry. All over the world the Indian ethnic designs and materials are shining by million facets. Currently designer made and custom made apparels calculated to be reach about Rs.20,000 crore in coming years. Many international designers and brands are spreading their empires in India with the help of globalisation and Foreign Direct Investment (FDI). Indian fashion and textile industry is playing a catch up in research and investigation required to match upcoming business and customer needs. 
Technology is key driver in all aspects of consumer business whether its personal care, healthcare, digital payments and fashion is not far behind as well. That is why we see inventions put to use in form of wearable technologies which has sparked interest in media as well as aroused customer interests in interactive technologies. This highlights wearable technologies progressing from margin to mainstream.

\section{What are Wearable Technologies?}

Wearable technology consists of very small devices worn on the body; these devices are able to store and process data about the wearer. They are also known as "Wearable Computers". These technologies are user friendly hence provides accessibility and convenience after wearing on body and provides the information very quickly and periodically. The more exciting about these technologies that they are embeddable, ingestible, hearables and also flexible and can bend in to human skin as second skin. What has been the Evolution Journey of Wearable Technologies? Going back in history of wearable technologies, first known example is watch being used in necklaces in the 15th century and later being transformed into pocket watch once waistcoats came in to fashion and adopted. In 17th century, Chinese inventor created a finger ring mounted with an abacus on it. During World War-I, Pigeon photography, an aerial photography method along with wearable technology was used to capture images of enemy troops. In 1904, the aviator Alberto Santos-Dumont pioneered the use of the wrist watch as he could free his hands from holding watch while flying his plane. This established wearing a watch on wrist is more convenient and led to adoption world-wide. We have seen a calculator watch greatly adopted and being a famous possession in the 1980's. Hearing aids also have been another example of early adoption of wearable technology.

What is Current Scenario?

Modern day wearable technology is getting incorporated in daily lifestyle. Researchers and pioneers of wearable technology have tried to extend its usage in form of accessories, clothing etc. This technology is being used for tracking steps and movements, monitoring heart rates, secretly recording voice and spy videos through hidden devices, keeping track of criminals using collars or even wild animals being tracked through electronic collars. Wearable technologies have gained lot of importance in defence sector with helmet mounted cameras and smart display for aircraft pilots. In the fashion arena, a great example of innovation is an award winning concept of Bluetooth-connected electronics garment called the "Hug Shirt" at the Cyber Art Festival in Bilbao, Spain. The Hug Shirt created by Cute Circuit, is designed for tele-transmitting touch (hugs) over distance. This pioneering technology differs from previous early wearable technology like watches, helmets etc. due to implementation of the device in form of clothing. The latest development shows new sensors being created to fuse seamlessly with human body. Healthcare industry is leveraging in advanced sensor technology which is giving rise to new forms of health monitoring and treatment. For example a new wearable sensor that can measure salts like sodium, potassium, glucose from sweat which has been created by experts in University of California. New sensors prototypes are being created which can be placed around human hears, can be implanted in brain, and sensors with ability to stretch or contract like human skin. "The goal is really to blur the distinction between man-made electronic systems and biology," quoted by John Rogers (2013), a material scientist based out the University of Illinois at Urbana-Champaign.

\section{Implementing Wearable's Technologies}

Fashionable wearable technologies can be defined as garments and accessories that are designed for combined aesthetics and style, further embedded with functional technology using one or more sensors. The method allows possibilities for the dynamic customization of apparel for functional application. Further there are textiles being produced material other than convention fabrics which can conduct energy, transform and communicate. This clothing with embedded electronic components is also known with term "Smart Fabric or Smart Textile". Smart fabrics enable a direct interaction with the user and sense customer moves. Earlier fashionable wearable's were functional but they lacked aesthetic value.Wearable's are growing to become more stylish and comfortable, and can change colour or form, using inputs from sensors in the apparel. Further examples are clothing that change 
temperature based on external conditions, and party dresses that light up and produce sounds. Engineers and designers and engineers continue to explore by pushing the limits for fusing fashion and technology together. Technology is being used in an endeavour to capture accurate body measurements which are then utilized by ecommerce platforms to help end customers choose right fit and design of apparels. "Zozo" a fashion retailer in Japan developed a full body suite with dots to capture body dimensions using a mobile phone camera. Using the suite the customer body dimensions were captured produce custom apparel for individual customer needs. Although idea was novel, the deliveries were late than the promised two week period, further the customer complained about fitment being no better to standard sizes. The lead to stopping sale of the suite in Japan however the company did benefit with large customer database with body dimensions which would help improve their reach and also develop better fitting apparels. The company also claimed that the body measurement methodology was largely successful and that the supply chain was not able to scale up to the requirements of global delivery which is now changed to more practical period of six weeks. Another example is of, MTailor.com which provides custom fit for their apparel collection. The process involved a simple collection of photos from the customer using their application available on mobile devices.

The application captures 17 different points for clothes and mentions that their machine learning algorithms provide $20 \%$ more accuracy than a professional tailor. The company provides a perfect fit guarantee for 90 days, else refunds the money. Other applications and retailers providing similar innovative feature and apparel products are Nettelo, SAIA from 3D Look which tries to capture the silhouette from photos shot by mobile cameras. Then algorithms extract the sizes applying corrections. These applications are cheaply accessible, faster and can be directly handled by end users as compared to use of full body scanners. Creating a virtual 3D body form on the mobile app takes a few steps.

- After changing into tight and body clinging clothes, consumers can place their camera phones at an appropriate height and distance.
- Once consumers stand in front of the camera, just need to click all angles of their body. If required adjustments can be made.

- The body measurements can be stored for future requirements. They will be able to compare their body data captured with other sizing systems.

- Consumers can easily capture any custom measurements like circumference, width or height.

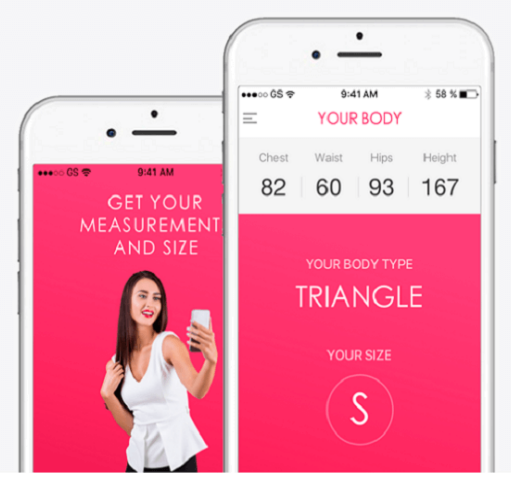

\section{Fig.1.Mobile apps extracting body measurements}

(Fig.1 Courtesy https://sourcingjournal.com/) Photo credit: 3D Look

This technology is portable, easy to use, and provides accurate output. This may save time, effort and even measuring errors while taking physical body measurements also serves consumers' fit and sizing problems. Now as a next step these measurements needs to act as input to retailers to leverage these measurements when consumers initiate shopping on e-commerce site. This will ensure great shopping experience for consumers and will also result in better satisfactions with respect to sizing and fitment. This will further lead to online apparel buying satisfaction with perfect fit and less pain for return.

\section{Conclusions}

Legacy technology scanners that require wearing tighter spandex like suites is inconvenient and is already taking a back seat. For the online retailers, the mobile applications processing photo snapped by end-users, using machine learning and image processing algorithms works best and is a cheaper option. As the technology evolves the accuracy of the measurement will increase. Soon all retailers will have such applications integrated into their ecommerce platforms to provide custom-fit garments made to measurements. For customers 


\section{www.rspsciencehub.com}

shopping in offline stores, full body scanners like ones produced by Vitronic can be made available in the stores where a customer walks in and measurements can be taken within a few seconds without any body contact. Further custom fit garments will be produced by cutting cloth to a custom size combined with cheap tailoring to deliver a great fit product. Obviously, companies using these techniques will have to be responsible for protecting and masking consumer identifiable data as well as data captured for body measurements. They will have to comply with legal obligations as directed by the governments of their respective countries. Some countries will still have restrictions in the capture and use of this data. With digital measurements comes higher convenience, lesser technicalities for end users making the process very fast and providing accurate measurements over the tape. The productivity of the digital measurement process is no match for manual tape-based measurements, where a number of users capture and upload measurements at any point in time; hence becoming a preferred choice of body measurements for customers and fashion industry.

\section{References}

\section{Journals}

[1].Ministry of Textile, Government of India, Annual report (2018-

19),http://texmin.nic.in/documents/annualreport

[2]. Ministry of Textile, Government of India, Annual report (2018-19), http://texmin.nic.in/documents/annual-report

[3]. Original stitch new body gram will measure your body, retrieved from, https://techcrunch.com/2018/07/02/originalstitchs-new-bodygram-will-measure-yourbody/

[4].Body Scanning Technology, https://www.sciencedirect.com/topics/engineer ing/ body-scanning-technology

[5].https://www.youtube.com/watch? $\mathrm{v}=\mathrm{CwwT5iR}$ $\mathrm{XVns}$

[6].https://www.youtube.com/watch?v=3ayYkJVi oZQ

[7].How Computer Vision Technology In Our Mobile Body Measurement App Tackle Perfect Clothing, https://www.abtosoftware.com/blog/computer-
Volume 03 Issue 01S January 2021

vision-technology-body-measurement-perfectclothing-fit

[8].New Sensors Fuse Wearable's with the Human Body, retrieved from, https://www.electronicdesign.com/technologie s/electromechanical/article/21801295/newsensors-fuse-wearables-with-the-human-body

[9].Measuring Up 3D Body Scanning Revolution And Its Impact On Apparel Sizing, retrieved from,

[10].https://sourcingjournal.com/topics/technology /measuring-up-3-d-body-scannings-revolutionand-its-impact-on-apparel-sizing-gs-68999/v

[11].Sibei Xia, Siming Guo, Jiayin Li \& Cynthia Istook, 2018, Comparison of different body measurement techniques: 3D stationary scanner, 3D handheld scanner, and tape measurement, The Journal of The Textile Institute, Volume 110, 2019, issue-8, https://www.tandfonline.com/doi/abs/10.1080/ 00405000.2018 .1541437 ?src $=$ recsys \&journalC ode $=$ tjti20

[12].World Leading 3d Body Measurement And $3 \mathrm{~d}$ Visualization, https://www.tc2.com/

[13].Electronic textiles or e-textiles, https://en.wikipedia.org/wiki/E-textiles

[14].Measuring Up: 3-D Body Scanning Can Now be Done on an iPhone, https://sourcingjournal.com/topics/technology/ measuring-up-3-d-body-scannings-revolutionand-its-impact-on-apparel-sizing-gs-68999/

[15].Portable $3 \quad$ D Scanners,https://www.artec3d.com/portable3d-scanners?utm_source =google\& utm_ mediumcpc\&utm_campaign $=7128745423 \& u t$ m_term $=\% 2 \mathrm{~B} 3 \mathrm{~d} \% 20 \% 2 \mathrm{Bbody} \% 20 \% 2 \mathrm{Bscann}$ er\%20for\%20\%2Bmeasurements||kwd335557369334\&utm_content $=78956010223 \| \&$ keyword $=\% 2 \mathrm{~B} 3 \mathrm{~d} \% 20 \% 2 \mathrm{Bbody} \% 20 \% 2 \mathrm{Bscann}$ er\%20for $\% 20 \% 2$ Bmeasurements\&gclid=EAIa IQobChMItezru8325wIVzzUrCh1TvwjkEAA YASAAEgIlQvD_BwE

[16].Figure 1 -Mobile apps extracting body measurements, Photo credit: 3D Look, retrieved from, https://sourcingjournal.com/) 